\title{
Abordagem do Tema "Violência contra a Criança" no Curso de Medicina da Universidade Federal Fluminense
}

\author{
The Approach of the Theme "Violence \\ against Children" in UFF Medical School
}

\author{
Lilian Koifman \\ Raquel Mendes de Menezes ${ }^{I I}$ \\ Karine Ramos Bohrer II
}

\author{
PALAVRAS-CHAVE: \\ - Recursos Humanos em Saúde; \\ - Educação Médica; \\ - Violência; \\ - Criança.
}

Recebido em: 09/06/2011

Reencaminhado em: 19/12/2011

Aprovado em: 21/03/2012

REVISTA BRASILEIRA DE EDUCAÇÃO MÉDICA
${ }^{I}$ Universidade Federal Fluminense, Niterói, RJ, Brasil; Universidade do Estado do Rio de Janeiro, Rio de Janeiro, Rj, Brasil.

"Universidade Federal Fluminense, Niterói, RJ, Brasil. 


\section{INTRODUÇÃO}

A agressão infantil é definida como "qualquer dano físico ou psicológico não acidental contra uma criança, ocasionado por seus pais ou cuidadores, decorrente de ações físicas, sexuais e/ou emocionais, de omissão ou permissão, e que ameaçam seu desenvolvimento normal, tanto físico como psicológico"1,2 (p. 110, p.40).

A problemática do tema violência doméstica é observada já na definição dessa expressão, uma vez que existe controvérsia entre os limites que vão do "tapinha" ao espancamento. Além disso, até os parâmetros éticos e pedagógicos sobre castigos e punições físicas reúnem pesquisadores de diferentes influências ${ }^{3}$.

Didaticamente, os tipos de violência doméstica são classificados como violência física, violência psicológica, negligência e violência sexual. Em determinados casos, pode haver somente um tipo de violência ou a sobreposição deles, quando são identificadas duas ou mais modalidades ${ }^{4}$.

Na sociedade brasileira atual, a punição física ainda é um instrumento muito frequente na educação dos filhos. Em determinadas circunstâncias, essa forma de disciplina defendida pelos pais pode favorecer a banalização e a cronicidade da violência física doméstica contra crianças e adolescentes. Para alguns pais, inclusive alguns profissionais, tais atos, por não serem considerados abusivos, serão reproduzidos como uma prática normal de disciplina. Segundo relatórios de atividades do Centro Regional de Atenção aos Maus-Tratos na Infância do ABCD (Crami), essa é a violência mais notificada, sendo que de 1988 a 2000 a modalidade representou $51 \%$ do total de notificações. Essa mesma pesquisa confirma a tendência, pois em $58 \%$ das famílias participantes, a violência física estava presente. $\mathrm{O}$ fato de este tipo de violência poder deixar marcas visíveis no corpo da criança faz com que haja uma justificativa para seu alto índice de notificação, diferentemente da violência psicológica, por exemplo. Isto é comprovado quando verificamos que esta última só é identificada com maior frequência quando associada à violência física, tornando-se o que chamamos de violência mista ${ }^{4}$.

A violência contra crianças e adolescentes é a primeira causa de morte na faixa de cinco a 19 anos e a segunda no período de um a quatro anos, sendo apontada como uma das principais causas de morbi-mortalidade na infância ${ }^{5,6}$. Isto confere ao tema grande repercussão e relevância, principalmente quando se trata da responsabilidade e dever da notificação pelo profissional de saúde, que, muitas vezes, não está apto a lidar com a situação.

Ramos e Silva ${ }^{7}$, em pesquisa realizada na cidade de São Paulo para identificar como profissionais da Estratégia Saúde da Família atuam ao se depararem com situações de violência doméstica contra a criança, descrevem que esses profissionais se sentem despreparados e desprotegidos para atender e resolver demandas de crianças vítimas de violência doméstica.

Outro estudo recente, realizado na cidade de Niterói por Rocha e Moraes $^{8}$, ratifica que a violência familiar contra a criança tem caráter permanente do ponto de vista epidemiológico. O objetivo do estudo foi estimar a prevalência e caracterizar a violência familiar contra crianças residentes nas regiões de abrangência do Programa Médico de Família de Niterói (RJ), discutindo possibilidades de atuação das equipes tendo em vista a prevenção, a deteç̧ão precoce e o acompanhamento de famílias em situação de violência. A mãe foi a principal autora de todos os tipos de maus-tratos, embora a maioria das crianças sofra agressões psicológicas e punições corporais de ambos os pais. Diante das altas prevalências e do envolvimento de toda a família nas situações de violência, o estudo aponta que o problema deve ser considerado prioridade na Estratégia Saúde da Família ${ }^{8}$.

No Brasil, há uma fragmentação da padronização para registrar situações de violência familiar, provocando prejuízos para uma rotina clara e eficaz, e dificultando os procedimentos que os profissionais e instituições devem seguir. Além disso, há carência de políticas públicas eficazes que viabilizem a criação e, principalmente, a manutenção de programas preventivos e de tratamento, necessários para promover o aprimoramento e evolução de técnicas eficazes no enfrentamento desse problema ${ }^{4}$.

O dimensionamento fidedigno do problema é um desafio a enfrentar, constituindo a etapa inicial para desenvolver programas com esse objetivo. Referimos-nos às questões relativas à identificação e à notificação dos casos.

\section{Acredita-se que uma parte das violências contra a infân- cia/adolescência nem seja reconhecida como tal, e ou- tra, mesmo que identificada, não é notificada. Ainda as- sim, verificou-se que no setor se suspeita de um número de casos bastante superior ao oficialmente conhecido, denotando que o problema maior é o da subnotificação, situação que é muito grave, na medida em que a noti- ficação é ação fundamental à proteção infantil ${ }^{9}$ (p. 337).}

Além disso, diversas pesquisas e estudos constataram que, por meio da correta notificação de casos suspeitos, é possível identificar situações de maus-tratos "latentes" ou em instalação, que podem se agravar ao longo do tempo. Se os tantos casos de violência encobertos e velados fossem revelados e avaliados, poderiam se tornar conhecidos e receber acompanhamento. Dessa forma, seriam dados os passos necessários à identificação precoce de problemas, consolidando ações de 
prevenção secundária. Concretamente, isto poderia significar a ampliação de oportunidades de real intervenção e prevenção de violência contra a criança ${ }^{9}$.

A complexidade do assunto é corroborada pelas sequelas, pouco visíveis e menos evidentes, produzidas nos campos moral, emocional e relacional dos envolvidos e que nem sempre são captadas em sua real extensão e profundidade pelo sistema de proteção e assistência de que dispomos no Brasil na atualidade ${ }^{10}$.

A violência familiar representa um importante fator de risco para o adequado desenvolvimento e integração social, embora seja frequentemente justificada pelos agressores como formas de educar e corrigir comportamentos indesejáveis ${ }^{11}$ (p. 851).

A violência é capaz de gerar problemas que podem durar toda a vida - principalmente problemas sociais, emocionais, psicológicos e cognitivos - e pode levar a comportamentos prejudiciais à saúde. Normalmente, tais comportamentos se manifestam por abuso de substâncias psicoativas, álcool e outras drogas, e iniciação precoce à atividade sexual, com maior exposição à gravidez precoce, à exploração sexual e à prostituição. Já em relação aos danos à saúde mental e social, crianças e adolescentes vítimas da violência podem sofrer distúrbios de ansiedade, transtornos depressivos, alucinações, baixo desempenho na escola e tarefas de casa, alterações de memória, comportamento agressivo, violento e até tentativas de suicídio. Além disso, a exposição precoce à violência pode estar relacionada com o comprometimento do desenvolvimento físico e mental, além de doenças durante a vida adulta, como as doenças sexualmente transmissíveis e a aids, bem como aborto espontâneo ${ }^{12}$.

Por esse motivo, concordamos com os autores que salientam que:

A compreensão de que a violência doméstica contra a criança e o adolescente é um "sintoma" modulado por dificuldades culturais, sociais, econômicas e das relações interpessoais, provocando conflitos nas relações familiares, devendo os cuidados serem extensivos a todo o grupo familiar ${ }^{4}$ (p. 148).

No Brasil, buscou-se avançar no campo dos direitos humanos e na tentativa de conhecer melhor a realidade da criança e protegê-la. Legitimando sua autonomia enquanto sujeito de direitos constitucionais, foi criado, na década de 1990, o Estatuto da Criança e do Adolescente (ECA). Esse conjunto de normas estabeleceu a obrigatoriedade da notificação compul- sória para os profissionais dos estabelecimentos do Sistema Único de Saúde (SUS), criando a Ficha de Notificação Compulsória de Maus-Tratos contra Criança e Adolescente, baseada nos artigos 13 e 145 do ECA ${ }^{1,4,13}$.

Os avanços obtidos até aqui foram importantes, uma vez que atenuaram o descaso concernente aos casos de violência contra crianças e adolescentes. Porém, são muitas as limitações encontradas, pois a padronização do registro das situações de violência familiar é fragmentada, resultando em deficiências nos procedimentos a serem seguidos pelos profissionais e instituições ${ }^{1}$.

A formação do profissional de saúde está centrada no conteúdo, e muitas universidades, preocupadas com o binômio saúde-doença, se afastam da dura realidade engendrada fora dos hospitais ${ }^{14}$. Isto resulta em despreparo dos estudantes para enfrentar situações mais delicadas como a violência intrafamiliar, cuja abordagem é negligenciada no durante a graduação. Em decorrência da falta de informações técnicas e científicas necessárias para diagnosticar casos de violência, ocorre a subnotificação, o que é patente no caso do Brasil, onde se estima que, a cada caso notificado, de 10 a 20 não são ${ }^{15}$.

Neste sentido, observa-se o predomínio de um agir profissional fragilizado pela ausência de crítica e preparo, que contribui para fragmentar a realidade familiar e comunitária ${ }^{10}$. Portanto, é imprescindível que o médico, desde sua formação, esteja familiarizado com as situações de abuso, uma vez que, nos contatos com crianças, se depara com essa realidade. Tal conhecimento irá contribuir para uma abordagem melhor da causa e seu diagnóstico, se decorrente de traumas acidentais ou intencionais. Isto é feito pelo exame e registro cuidadoso de cada ferimento e pela análise da coerência entre a lesão, a história apresentada e o estágio de desenvolvimento da criança. Se não houver acordo, o abuso tem de ser considerado, e a suspeita, relatada ${ }^{16}$.

\section{OBJETIVO}

O objetivo inicial do projeto de pesquisa foi fazer um levantamento sobre a abordagem do tema Violência contra a Criança no curso de graduação em Medicina da UFF. Além disso, nos propusemos a analisar a percepção dos alunos quanto a sua capacidade de lidar com o tema na vida profissional e a conhecer a experiência dos profissionais de saúde formados pela UFF nos casos de violência contra a criança.

Com base nesse estudo inicial, participamos da produção de recursos pedagógicos para serem utilizados em disciplinas do curso de Medicina.

\section{METODOLOGIA}

O projeto foi iniciado em 2008, após a aprovação pelo Comitê de Ética da Universidade Federal Fluminense. 
A seleção dos entrevistados foi feita de forma aleatória, sendo abordados individualmente nos corredores da universidade. Os selecionados que aceitaram participar foram levados a uma sala reservada, onde era explicado o trabalho e garantida a não identificação do participante. Após a assinatura do Termo de Consentimento Livre e Esclarecido, eram entregues os questionários de autoavaliação elaborados de forma objetiva. Os entrevistadores ficavam ao lado do participante para solucionar eventuais dúvidas a respeito das questões. No fim da entrevista, o participante ficava livre para dar sua opinião e sugestões sobre o tema e o trabalho.

Inicialmente, em 2009, o projeto foi realizado por meio de entrevistas com 24 alunos de Medicina da UFF (dois alunos de cada período); cinco professores da área de Pediatria; e cinco residentes de Pediatria do Hospital Universitário Antônio Pedro, que necessariamente se formaram na UFF. Após esta primeira fase, consultamos um especialista em estatística e fomos aconselhados a aumentar a amostra para que os resultados obtivessem maior significância estatística.

Assim, no ano de 2010, foram realizadas 140 entrevistas no total, sendo 120 estudantes (10 por período), 10 residentes do Hospital Universitário Antônio Pedro, necessariamente formados pela UFF (cinco de Pediatria e cinco de outras áreas) e 10 docentes (cinco de Pediatria e cinco de outras áreas). A escolha dos residentes e docentes de acordo com a área foi feita para que fosse possível comparar os profissionais da Pediatria com os de outras áreas. Ao final, as entrevistas foram analisadas por meio de um estudo quantitativo e qualitativo.

\section{RESULTADO}

\section{Entrevistas com Alunos}

Em relação ao contato com o tema da Violência contra a Criança em sua vida pessoal ou profissional, a maioria (53\%) dos alunos declarou nunca ter tido. Porém, observando esse resultado de acordo com cada fase da formação, os alunos do internato destoam dos alunos do primeiro ao quarto ano, uma vez que $40 \%$ daqueles relataram ter tido contato com o tema após o início do curso. Esses números nos levam à conclusão de que, ao chegarem ao internato, os alunos entram em contato com casos de violência contra a criança na prática, ou seja, têm mais essa vivência quando comparados aos alunos das fases anteriores.

A grande maioria dos alunos (64\%) relata que somente teve o tema abordado na Faculdade de Medicina, sendo que, entre os alunos do terceiro e quarto anos, esse resultado abrange um número significativo (83\%). Isto se deve ao fato de que é principalmente nessa fase do curso que os alunos assistem às aulas específicas sobre o tema.
Quando indagados em quais disciplinas se recordam de ter sido abordado o tema, no primeiro e segundo anos os alunos se referem às disciplinas Trabalho de Campo Supervisionado e Saúde e Sociedade. Enquanto isso, entre os alunos do terceiro e quarto anos e internato, as disciplinas mais citadas foram Pediatria e Neuropsiquiatria Infantil. A provável explicação para esses resultados é que os alunos do terceiro e quarto anos e internato, durante as aulas de Pediatria, consolidaram mais o tema do que na disciplina Saúde e Sociedade. Já a maior referência à disciplina Trabalho de Campo Supervisionado pelos alunos do primeiro e segundo anos se deveria à inclusão, em 2009, do tema Violência contra a Criança em um dos grupos da disciplina. Desta forma, os alunos de períodos mais avançados não tiveram contato com o tema nesta disciplina.

Dos alunos que se referiram a contatos com o tema fora do curso de Medicina, a maioria citou os meios de comunicação, seguidos de convívio social. Os alunos do primeiro e segundo anos citaram também palestras escolares, e os alunos do terceiro e quarto anos e internato relataram contato considerável com o problema em plantões. Esse dado se deve ao fato de o aluno de Medicina costumar ter mais prática clínica em plantões à medida que avança no curso.

Do total de alunos, somente $9 \%$ disseram que o tema foi bem abordado e não apresentaram dúvidas a respeito. Entre os alunos do primeiro e segundo anos, a grande maioria (71\%) alega que teve o tema abordado superficialmente, mas acreditava que seria mais bem abordado até o final da graduação. Os alunos do terceiro e quarto anos do curso e do internato responderam em sua maioria (38\% e 53\%, respectivamente) que o tema foi abordado superficialmente e não acreditavam que seria visto mais profundamente até o final da graduação. Nota-se, também, que há uma progressão do primeiro e segundo anos do curso de Medicina ao internato em relação a esse quesito. Isso pode ser explicado pelo fato de que, os alunos, ao iniciarem a faculdade, têm esperança de que o tema seja abordado ao longo do curso. Em contrapartida, os alunos em períodos avançados não têm mais esta expectativa, uma vez que somente $6 \%$ deles acreditam que o tema será abordado de melhor forma até o final da faculdade.

A maioria dos alunos (44\%) alega não se sentir preparada para lidar com a questão na vida profissional, mas acredita que até o final do curso estará. A análise por fase de formação mostra que há um decréscimo do primeiro e segundo anos ao internato $(73 \%, 50 \%, 10 \%$, respectivamente), ou seja, ao longo da graduação, os alunos perdem a esperança de se tornar aptos a lidar com o tema. Paralelamente, há uma progressão (8\%, $33 \%, 45 \%$ ) dos alunos que não acreditam que ao final do cur- 
so estarão preparados. No internato, a maioria (30\%) se sente preparada somente para a identificação do caso.

$\mathrm{O}$ fato de alguns alunos do primeiro e segundo anos terem respondido que se consideravam plenamente preparados para abordar o tema, sabendo como identificar o paciente e como encaminhá-lo ao respectivo serviço, pode ser explicado pelo tema da Violência contra a Criança ter sido recentemente inserido na disciplina de Trabalho de Campo Supervisionado 1, dando a esses alunos uma visão mais ampla sobre a questão. Nenhum aluno do terceiro e do quarto ano relatou se sentir plenamente preparado, e os que mais se sentem preparados são os alunos do internato, embora em número relativamente baixo (15\%).

Os alunos foram também questionados sobre quais seriam os quesitos que provocaram a deficiência no aprendizado, com as opções: falta de aula específica sobre o tema; falta de ênfase na identificação dos casos; falta de ênfase na conduta correta a ser tomada diante do caso; falta de vivência prática nos ambulatórios/ emergência/maternidades/escolas/creches. Entre todos os alunos, $34 \%$ assinalaram que a falta de vivência prática foi o que mais provocou deficiência no aprendizado.

Houve equilíbrio entre todas as respostas dos alunos do primeiro e segundo anos, o que não ocorreu entre os alunos do terceiro e quarto anos, cuja maioria (43\%) se referiu à falta de vivência prática. Por outro lado, entre os alunos do internato, a falta de ênfase na conduta a ser adotada foi considerada a mais relevante deficiência. Esses resultados mostram que os alunos, nas primeiras fases da formação, sentem falta de todos os quesitos; os do terceiro e quarto anos se referem principalmente à falta da abordagem prática; e os alunos do internato, que já têm maior experiência prática, apontam principalmente uma falha mais pontual e teórica da abordagem do tema.

\section{Entrevista com Professores}

Dos dez professores entrevistados, cinco não abordam o tema porque, segundo eles, não se enquadra em sua disciplina, sendo destes quatro professores de áreas diversas e um professor de Pediatria. Outros cinco professores, todos de Pediatria, relataram sempre abordar o tema em uma aula específica sobre violência. Esse resultado mostra que muitos professores acreditam que o tema não diz respeito a áreas da Medicina que não lidam diretamente com crianças. Não percebem que, independentemente da área de atuação, todo profissional de saúde pode um dia se deparar com esses casos, tendo, portanto, obrigação de saber como agir. Ainda observamos uma falha mais grave quando um professor de Pediatria alega que, por lidar somente com neonatologia, o tema não é pertinente em suas aulas. Isto mostra seu despreparo a respeito do tema, uma vez que, no dia a dia dos serviços de saúde, se observam inúmeros casos de agressão à gestante, abandono de recém-nascidos, etc.

Dos cinco professores que relataram abordar o tema, quatro enfocaram principalmente a identificação do caso, e apenas um respondeu que, além da identificação, propõe e discute a conduta a ser adotada. Esse dado corrobora o resultado da entrevista com os acadêmicos, uma vez que, ao final de sua formação, os alunos constatam que sua maior dificuldade reside na correta conduta perante casos de Violência contra a Criança. As respostas dos professores parecem ratificar falhas do ensino no que diz respeito ao tema que analisamos, o que se reflete diretamente na formação dos alunos e em seu desempenho profissional.

Os dez professores entrevistados consideram que o tema é muito importante e que os alunos precisam de melhor formação nessa área. Entretanto, embora reconheçam a importância do tema e saibam que os alunos são carentes desse aprendizado, muitos professores acreditam que não lhes cabe a responsabilidade sobre tal ensinamento.

\section{Entrevistas com Residentes}

$\mathrm{Na}$ análise dos dados das entrevistas com os dez residentes, percebemos que as respostas foram divergentes: um dos residentes relata que não teve o tema abordado no curso de Medicina; três tiveram o tema abordado com enfoque apenas na identificação dos casos; e cinco tiveram o tema abordado com enfoque na identificação dos casos e na conduta correta a ser seguida. Somente um relatou que teve o tema plenamente abordado. Não houve diferença entre as respostas, em função da especialidade médica da residência, neste quesito.

Dos residentes entrevistados, cinco ainda não tiveram experiência em situação relativa ao tema, três tiveram somente uma experiência com criança vítima de violência, e dois tiveram até três experiências. Todos os residentes que já tiveram tal experiência são da área de Pediatria. A nosso ver, estas respostas podem levar a duas conclusões: ou os casos de violência infantil não chegam às outras áreas ou esses casos podem ter passado despercebidos por profissionais de áreas não ligadas à Pediatria

Dentre os cinco residentes que relataram ter tido experiência com pacientes vítimas de violência, um afirmou ter se sentido seguro na identificação do caso, mas inseguro quanto à conduta correta a ser seguida. Quatro relataram que souberam como agir e se sentiram muito seguros. É importante enfatizar que esse quesito não visava avaliar se a conduta seria correta ou não. Contudo, cabe observar que, em alguns casos, mesmo quando o relator falava de segurança na atuação, a conduta descrita fugia à recomendada pelos especialistas da área. 


\section{A INSERÇÃO DO TEMA NA FACULDADE DE MEDICINA}

Diante dos resultados, confirmamos a necessidade de incorporar ao currículo de Medicina formas de amenizar o déficit teórico e prático com relação ao tema da Violência contra a Criança, que atinge os alunos como um todo.

É importante ressaltar que este estudo teve início em 2009 com respostas discursivas sobre o mesmo tema, mas com um pequeno número de estudantes e professores entrevistados. Fomos aconselhadas a aumentar a amostra após consulta a um especialista em bioestatística, para melhor formatar os achados quantitativos da pesquisa, uma vez que eles nos conduziriam a uma análise qualitativa. Desta forma, propusemos uma segunda etapa de pesquisa, dando continuidade àquela iniciada em 2009, ampliando a significância estatística.

As disciplinas Saúde e Sociedade 1 e Trabalho de Campo Supervisionado 1 e Trabalho de Campo Supervisionado 2 são oferecidas ao curso de Medicina pelo Instituto de Saúde da Comunidade. As duas primeiras trabalham os temas de Saúde e Cultura e Integralidade. A disciplina Trabalho de Campo Supervisionado 1 utiliza diversos exemplos de questões de saúde ou faixas etárias, com metodologia ativa, na qual os alunos do primeiro período são divididos em grupos de dez e orientados por um preceptor (em sua maioria, docentes do Instituto de Saúde da Comunidade) e levados a construir, a cada semestre, o cronograma de leituras e visitas a campo. Cada grupo estuda, ao longo de um semestre, um tema específico e, no final do período, transmite o que aprendeu ao resto da turma em um seminário (para mais detalhes, ver artigos que descrevem a disciplina ${ }^{17,18,19}$ ).

Em 2009, participamos ativamente da inclusão do tema da Infância na disciplina Trabalho de Campo Supervisionado 1, em que se abordou a questão da Violência contra a Criança. Inicialmente, é realizado um estudo teórico mediante leituras do Estatuto da Criança e do Adolescente, de cartilha sobre a Violência contra a Criança, de artigos sobre os tipos de violência e estudos sobre as consequências da violência infantil na vida adulta. Os alunos têm ainda a oportunidade de realizar encontros com profissionais especializados no tema e de vivenciar esta realidade no Conselho Tutelar de Niterói, quando obtêm novas informações e aprendizado prático, e tomam conhecimento da responsabilidade social que os profissionais de saúde são obrigados a assumir.

$\mathrm{Na}$ entrevista realizada com alunos dos primeiros períodos antes da inserção do tema (início de 2009), observou-se que houve abordagem em diversas disciplinas, mas ninguém se mostrou preparado para lidar com os casos. Por outro lado, as entrevistas feitas no início de 2010 mostram que a única disciplina citada foi Trabalho de Campo Supervisionado 1, e vários alunos se consideraram preparados para lidar com crianças vítimas de violência na prática.

\section{CONCLUSÃO}

Não há dúvida de que a formação do médico no campo da violência é precária ${ }^{20}$. Bourroul e Botazzo ${ }^{21}$ relatam que os profissionais afirmam que não estão preparados para lidar com vítimas de violência, e poucos reconhecem seu papel no tratamento. Afirmam, ainda, que questões específicas do próprio profissional, entre elas o medo, devem ser destacadas na formação, para que ele possa ser preparado para desempenhar sua função ${ }^{21}$.

Concordamos com os autores quando afirmam que:

Uma formação socialmente contextualizada, que promova uma articulação estreita entre o mundo do ensino, do trabalho e a realidade, poderá instrumentalizar os profissionais para o enfrentamento de problemas e das reais necessidades de saúde da população $0^{20}$ (p.330).

A análise dos dados encontrados em nossa pesquisa mostrou que a maioria dos alunos afirma que o tema da Violência contra a Criança foi abordado na graduação, mas de forma ainda insuficiente, pois continua com dúvidas e insegurança. Verificou-se, também, que a maioria dos alunos dos primeiros anos do curso acredita que até o final da graduação estará preparada para lidar com o tema. Em contrapartida, a análise das entrevistas mostra que, nos períodos mais avançados, alguns estudantes continuam se sentindo inseguros para lidar com as situações concretas de violência contra crianças quando as presenciam nas disciplinas práticas.

Apesar disso, já observamos resultados positivos com a inserção do tema na disciplina de Trabalho de Campo Supervisionado 1, que propiciou a oportunidade de estudar e vivenciar o cenário da violência contra crianças, levando os alunos a se sentirem mais bem preparados para lidar com suas vítimas na prática médica. Lamentavelmente, a maioria dos alunos não teve essa oportunidade, e a grande maioria ainda se sente despreparada. Como relatamos, no final do semestre da disciplina Trabalho de Campo Supervisionado 1, os alunos apresentam uns aos outros os temas trabalhados nos pequenos grupos, em forma de seminários. Esse momento é muito útil para compartilhar os conteúdos aprendidos no grupo de Infância, mas ainda nos parece insuficiente.

Foi apurado que, entre os docentes com formação em Pediatria, a maioria relata abordar o tema em aula. Entre residentes da mesma área, a maioria revela ter tido contato com casos na prática e que teve segurança para atuar.

Nas referências levantadas, encontramos diversos autores que corroboram nosso estudo. Segundo Bourroul e Botazzo ${ }^{21}$ : 
A quase totalidade dos residentes entrevistados expressou medo e caracterizou a formação como insuficiente. As falas dos sujeitos sugerem discriminação e estranhamento diante do outro, caracterizando situação onde sociedades diferentes aparecem como ameaçadoras (p. 737).

Ainda ratificando nossos resultados, a pesquisa de Bourroul e Botazzo ${ }^{21}$ mostrou que há, por parte dos aparelhos formadores, preocupação com o tema e, por outro lado, necessidade de conhecimento, uma vez que a maioria dos residentes entrevistados reconheceu várias oportunidades de aprendizado em disciplinas da graduação e quase a totalidade citou contato com casos sob suspeita de violência nos estágios de pronto-socorro da residência. Todavia, durantes suas entrevistas, esses autores concluem que tanto o descontentamento em relação à suficiência deste aprendizado quanto a escassez das atribuições do pediatra diante da violência doméstica contra crianças e adolescentes (VDCA), reconhecidas pelos residentes, apontam algo não esgotado. Referem ainda que o medo não reconhecido (ou desconhecido) por parte dos formadores, e tão prevalente entre os residentes, se mostrou um possível bloqueador do aprendizado e, consequentemente, do desempenho que deve ser trabalhado para experimentar novos resultados ${ }^{21}$.

Em outro estudo que vem corroborar essa ideia, Pires ${ }^{22}$ afirma que o pediatra, quando comparado com outros trabalhadores da saúde, tenderia a subavaliar a gravidade dos maus-tratos, notificando-os com menor frequência.

No Brasil, não encontramos referências a estudos quantitativos sobre fatores relacionados à identificação e notificação pelos pediatras de maus-tratos infantis ${ }^{22}$. No estudo qualitativo de Almeida ${ }^{23}$, o despreparo técnico e a desconfiança nos órgãos de proteção foram apontados como as maiores dificuldades para a notificação. Esse estudo aponta primeiramente um achado contraditório:

apesar da alta taxa de desconfiança nos órgãos de proteção e do medo do pediatra de ser envolvido em um processo legal, a identificação e a notificação de casos de maus-tratos infantis são uma prática frequente entre os profissionais. (p. 107)

A decisão de notificar dependeu principalmente do grau de conhecimento sobre maus-tratos infantis ${ }^{23}$.

Nossos objetivos foram parcialmente atingidos com a pesquisa. Além do mapeamento do estado da arte com relação ao tema da Violência contra a Criança na formação médica e do levantamento da opinião e percepção dos discentes, docentes e residentes sobre seu conhecimento sobre o tema, planejamos realizar outras atividades.
Para dar continuidade ao processo de aprendizagem dos alunos, do corpo docente e dos residentes, temos a proposta de organizar a "Semana de Combate aos Maus-Tratos à Criança", uma atividade que oferecerá informações a toda a faculdade, desde os primeiros períodos até o internato, com distribuição de materiais informativos com dados estatísticos não só das famílias mas também de Saúde Pública, na qual os profissionais da saúde têm compromisso, responsabilidade e dever.

Como esta pesquisa foi realizada a partir de um projeto de Iniciação Científica, no qual os alunos envolvidos, nas diversas etapas, sempre compartilharam as atividades de pesquisa com as demais atividades do curso médico, não foi ainda possível executar a última tarefa descrita. Ela será organizada e realizada em continuidade ao trabalho iniciado.

Pretendemos apresentar à direção da Faculdade de Medicina a proposta de realização periódica de eventos sobre o tema, que certamente poderá complementar o aprofundamento do tema na formação em saúde.

\section{AGRADECIMENTOS}

Agradecemos às alunas Patrícia Vieira Palácios Bagalho e Lídia Valente Dima, que participaram desta pesquisa em seu primeiro ano.

Pesquisa apoiada pela Fundação de Amparo à Pesquisa do Estado do Rio de Janeiro — Processo: E-26 100.905/2009. Número de Registro no SISNEP: 0064.0.258.000-08.

\section{REFERÊNCIAS}

1. Bazon MR. Maus-tratos na infância e adolescência: perspectiva dos mecanismos pessoais e coletivos de prevenção e intervenção. Ciênc saúde coletiva. 2007; 12(5):1110-2. p.1110.

2. Bringiotti MI. La escuela ante losniños maltratados. Buenos Aires: Editorial Paidós; 2000. p.40.

3. Neves MAS, Romanell G. A violência doméstica e os desafios da compreensão interdisciplinar. Estudos de Psicologia. 2006; 23(3):299-306.

4. Brito AM, et al. Violência doméstica contra crianças e adolescentes: estudo de um programa de intervenção Ciênc saúde coletiva. 2005; 10(1):143-9. p.148.

5. Sociedade Brasileira de Pediatria. Centro Latino-Americano de Estudos de Violência e Saúde Jorge Carelli. Escola Nacional de Saúde Pública. Fundação Oswaldo Cruz. Secretaria do Estado dos Direitos Humanos. Ministério da Justiça. Guia de atuação frente a maus-tratos na infância e adolescência: orientação para pediatras e demais profissionais de saúde. 2ª ed. Rio de Janeiro; 2001 
6. Garbin CAD, Queiroz APDG, Costa AA, Garbin AJI. Formação e atitude dos professores de educação infantil sobre violência familiar contra criança. Educ rev. 2010;(2): 207-16.

7. Ramos MLCO, Silva AL. Estudo sobre a violência doméstica contra a criança em unidades básicas de saúde do município de São Paulo - Brasil. Saude soc. 2011;20(1):136-46.

8. Rocha PCX, Moraes CL. Domestic violence against children and prospects for intervention of the Family Health Program: the experience of the Family Doctor Program/ Niterói (RJ, Brazil). Ciênc saúde coletiva. 2011;16(7):32853296.

9. Faleiros JM, Matias ASA, Bazon MR. Violência contra crianças na cidade de Ribeirão Preto, São Paulo, Brasil: a prevalência dos maus-tratos calculada com base em informações do setor educacional. Cad Saúde Pública. 2009;25(2):337-348. p.37.

10. Ferriani MGC, Ribeiro MA, Reis JN. Violência sexual contra crianças e adolescentes: características relativas à vitimização nas relações familiares. Cad Saúde Pública. 2004 ; 20(2): 456-464.

11. Abranchez CD, Assis SG. A (in)visibilidade da violência psicológica na infância e adolescência no contexto familiar. Cad Saúde Pública. 2011; 27(5):843-854. p.851.

12. Ministério da saúde. Brasília - Impacto da violência na saúde das crianças e adolescentes. Distrito Federal; 2008

13. Ferreira AL, Schramm FR. Implicações éticas da violência doméstica contra a criança para profissionais de saúde. Rev Saúde Pública. 2000; 34(6):659-65;

14. Moura ATMS, Reichenheimm E. Estamos realmente detectando violência familiar contra a criança em serviços de saúde? A experiência de um serviço público do Rio de Janeiro, Brasil. Cad Saúde Pública. 2005; 21(4):1124-1133;

15. Miyazaki MCOS, Pires ALD. Maus-tratos contra crianças e adolescentes: revisão da literatura para profissionais da saúde. Arq Ciênc Saúde 2005; 12(1):42-9;

16. Scherer EA, Scherer ZAP. A criança maltratada: uma revisão da literatura. Rev latino-am enferm. 2000; 8(4): 22-29.

17. Koifman L, Wong Un JA. Construindo saberes recíprocos: ética e técnica na prática educativa em saúde. In: Roseni Pinheiro e Ruben Araújo de Mattos, org. Cuidar do Cuidado: responsabilidade com a integralidade das ações de saúde. $1^{\underline{a}}$ ed. Rio de Janeiro: CEPESC: IMS/UERJ: ABRASCO, 2008. p. 251-266.

18. Koifman L, Paula RM, Alves TO. Integralidade na formação médica: relato de experiências na Coordenação de
Aids do HUAP. In: Pinheiro R, Mattos AR, org. Ateliê do cuidado: trabalhos completos / VII Seminário do Projeto Integralidade: saberes e práticas no cotidiano das instituições de saúde. $1^{\underline{a}}$ ed. Rio de Janeiro: CEPESC: IMS/UERJ: ABRASCO, 2008. p. 331-43.

19. Saippa-Oliveira G, Koifman L, Pontes ALM. As Agendas Públicas para as Reformas e sua Releitura no Cotidiano das Práticas da Formação: o caso da disciplina Trabalho de Campo Supervisionado. In: Pinheiro R, Mattos AR, org. Construção Social da Demanda - Direito à saúde, Trabalho em Equipe, Participação e Espaços Públicos. Rio de Janeiro: CEPESC: IMS/UERJ: ABRASCO; 2005. p. 129-45.

20. Souza ER, Ferreira AL, Santos NC. Concepções de docentes em relação ao manual sobre violência intrafamiliar. Rev bras educ med. 2009; 33(3):329-338.p.330.

21. Bourroul MLM, Rea MF, Botazzo C. Pediatric residents confronted with domestic violence against children and adolescents. Interface comunic saúde educ. 2008;12(27):73748.p.737.

22. Pires JM, et al. Barreiras, para a notificação pelo pediatra, de maus-tratos infantis. Rev Bras Saude Mater Infant. 2005; 5(1):103-108.

23. Almeida EC. Violência doméstica: um desafio para a formação do pediatra. Rio de Janeiro; 1998. Mestrado [Dissertação] - Universidade do Estado do Rio de Janeiro.

\section{CONTRIBUIÇÃO DOS AUTORES}

Lilian Koifman participou como orientador de todas as etapas da pesquisa e na elaboração do artigo. Raquel M. de Menezes e Karine Ramos Bohrer participaram de todas as etapas da pesquisa e elaboração do artigo.

\section{CONFLITO DE INTERESSES}

Declarou não haver.

\section{ENDEREÇO PARA CORRESPONDÊNCIA}

Lilian Koifman

Universidade Federal Fluminense.

Rua Marquês de Paraná, 303/3ํandar-Prédio Anexo do HUAP

Centro - Niterói

CEP. 24030-210 RJ

E-mail: liliankoifman@hotmail.com 